\title{
Intergroup Contacts, Neighborhood Diversity, and Community Trust: the Asymmetrical Impact of Negative and Positive Experiences
}

\section{Susanne Wallman Lundåsen ${ }^{1}$ (D)}

Accepted: 25 December 2021 / Published online: 7 February 2022

(c) The Author(s) 2022

\begin{abstract}
Intergroup contacts can occur in many different places but are often studied only limited to a specific context. This study contributes with data that taps intergroup contacts that occur in both the private and the public sphere, using data from a largescale survey directed towards individuals nested within 36 different municipalities and over 1,250 different neighborhoods with varying levels of visible minorities. The results also showed that just using the mere frequency of intergroup contacts is not sufficient to understand its association with community trust. Intergroup contacts that occurred in the neighborhood and in civil society organizations had a statistically significant association with community trust, while intergroup contacts that occurred in schools/workplaces and at home did not. The results also indicated that the neighborhood context moderated the impact of intergroup contacts. Whether contacts generated negative experiences mattered. Negative experiences mattered more for community trust especially for those who lived in diverse neighborhoods. The results indicated an asymmetry between the importance of positive and negative experiences of intergroup contacts for community trust.
\end{abstract}

Keywords Community trust $\cdot$ Neighborhoods $\cdot$ Intergroup contacts $\cdot$ Contact valence $\cdot$ Mixed models $\cdot$ Sweden $\cdot$ Diversity

\section{Introduction}

Under what circumstances do intergroup contacts contribute to trust in others in the local community? Many West European societies have populations that are increasingly diverse, mainly due to immigration. Concurrently, studies have indicated that diversity, especially in the neighborhood context, is correlated with lower levels of

Susanne Wallman Lundåsen

Susanne.wallman.lundasen@liu.se

1 Centre for Local Government Studies, Linköping University, Norrköping, Sverige 
first and foremost trust in others within the local community (Dinesen et al., 2020; van der Meer \& Tolsma, 2014). Community trust is defined as trust in others in the geographically bounded local community. Community trust is in itself an important collective resource that can explain the willingness to cooperate to solve problems within the local community (Wollebæk et al., 2012). Hence, with higher levels of community trust, it becomes easier to address problems that occur within the local community that require collective action.

Distrust is often argued to be born out of negative stereotyping (Hardin, 2003), feelings of threat from other groups (Stolle et al., 2008) or from intergroup conflicts (Hainmueller and Hopkins, 2014). Intergroup contacts are often suggested to dampen levels of hostility and intolerance towards others in diverse communities (Dinesen et al., 2020). Intergroup contacts in the present study are defined as having some sort of social and/or verbal interaction with someone of a different nationality. Many previous studies have found a positive relationship between intergroup contacts and tolerance towards other groups (Pettigrew \& Tropp, 2006). However, early on studies of intergroup contacts also included the condition that for intergroup contacts to enhance tolerance, they must occur under "optimal conditions," meaning that the groups should have equal status in a given context and ideally cooperate towards a common goal (Allport, 1954). But, as already specified by Laurence et al. (2018), where these intergroup contacts occur may also matter because different contexts (e.g., neighborhoods vs. workplaces) may differ considerably in how they manage to facilitate positive intergroup relations. Moreover, there may not be a perfect correlation between tolerance and trust, as trust could be viewed as further reaching in a social relationship. Alternatively, it is possible to tolerate someone and, concurrently, be uncertain about whether that person is trustworthy or not (Uslaner, 2015). It is still debated whether and under what conditions intergroup contacts impact trust (Thomsen et al, 2021; Finseraas et al, 2019; Dahl \& Abdelzadeh, 2017). As meta studies have suggested that community trust is more malleable and susceptible to neighborhood diversity than generalized trust or outgroup trust (Dinesen et al., 2020; van der Meer \& Tolsma, 2014), the present study therefore focuses on community trust as community trust potentially benefits the most from intergroup contacts. Previous studies have also called upon further studies that relate intergroup contacts to small geographical units such as neighborhoods (Bentsen, 2021).

Previous studies have often analyzed intergroup contacts that occur in one or two different places, thus providing a somewhat limited view of intergroup contacts that may occur in daily life. Therefore, to better reflect intergroup contacts that occur during daily life, we argue that it is necessary to focus on both the private sphere of the home and more public spheres such as school/workplaces, civil society organizations, and contacts that occur in neighborhoods. We argue that the sum of these contacts may provide a multitude of experiences that to a varying degree are related to trust towards others in the local community.

Against this backdrop, this study contributes with a more holistic understanding of under what circumstances intergroup contacts that occur across different spaces contribute to community trust. This is done by empirically investigating the role of where intergroup contacts occur, the valence of the contacts, and the moderating impact that neighborhood diversity may have on community trust. The empirical 
study is guided by three different research questions: (1) Do intergroup contacts in certain places matter more for community trust? (2) To what extent does the valence of intergroup contact matter for community trust? (3) Are intergroup contact and contact valence more salient for community trust among individuals who reside in diverse neighborhoods?

The study used survey data collected in 2017 , with over 10,000 individuals nested in 36 municipalities and slightly above 1,250 neighborhoods in Sweden. The study compared four different places (e.g., the home, workplaces/schools, and neighborhood) in which intergroup contacts occur, thus giving a more holistic view of the daily life of respondents. The data were analyzed using mixed models that take into account the nested structure of the data set.

Many influential studies on the associations between intergroup contacts and community trust have been carried out in countries with a colonial past (e.g., the Netherlands or the UK) or in the USA which has a long history of immigration. We argue, in line with Hopkins (2010), that results from studies carried out in contexts with a different trajectory to diversity cannot automatically be translated into other contexts, rather their validity needs to be empirically tested as the political contexts at the country level and at the local level may impact intergroup relations. Therefore, it is important to compare the importance of diversity and intergroup contacts within the same country context. The Swedish case offers an interesting empirical setting as the country has changed from being regarded by external observers (Delhey \& Newton, 2005) as being religiously and ethnically quite homogeneous to becoming more diverse. In 2010, first-generation immigrants comprised about $11 \%$ of the total population compared to approximately $20 \%$ in 2019 (Statistics Sweden, 2020). A large share of the increase has occurred through influx of refugees (from, e.g., Afghanistan, Ethiopia, Eritrea, Iraq, Somalia, and Syria) and family reunification of refugees. At the same time, Sweden is a high trust country. Over $60 \%$ of the population agree with the statement that most people can be trusted (EVS/WVS 2021). Swedes, according to some cross-national studies, are also more likely to include people of different nationalities or religions in their radius of trust (Delhey et al., 2011). Testing theories on the importance of intergroup contacts on trust in a high trust country like Sweden can therefore be considered a tough empirical test. Although studies of intergroup contacts have a relatively long history within social sciences, the field of studies that investigate the links between neighborhood diversity, intergroup contacts, and various forms of trust is far from settled (Christ et al., 2014; Laurence et al., 2019).

In what follows, an overview of the theoretical underpinnings of the study is presented, and hypotheses are formulated. This is followed by a methodological section. Thereafter, the results are presented, followed by a discussion of the conclusions.

\section{Theoretical Framework and Hypotheses}

In the classical study by Allport (1954), it was argued that intergroup contact can enhance tolerance between groups. Groups that interact face-to-face towards a common goal are less likely to be intolerant of each other. Studies have argued 
that intergroup contacts are also important at the macro level, such that those who belong to contexts in which intergroup contacts occur frequently are influenced by the behavior of others within the context (Christ et al., 2014). Whether others are regarded as being part of a different group or the same group may depend upon a number of factors such as upbringing (Uslaner, 2012) and also whether the political discourse accentuates differences between groups (Hopkins, 2010; Munobwa et al., 2021). The political debate may contribute to an increased awareness of differences such as national background. Recent studies from Sweden have shown an increased polarization of the population between those who perceive intergroup contacts to be mainly positive or mainly negative partly due to a harshened political discourse regarding migration and integration (Munobwa et al., 2021).

As specified by Laurence et al. (2018), the original contact theory tackled individual behavior and face-to-face contact, but its propositions were often extended to groups, such as neighborhoods. Intergroup contacts have been explicitly or implicitly inferred to occur in other diverse contexts, such as neighborhoods or schools (Laurence et al., 2018; Loxbo, 2018; Wallman Lundåsen \& Wollebæk, 2013). Other studies make a distinction by labeling what occurs at the context level as exposure to signal the possibility of residents only being withdrawn observers of diversity (Dinas et al, 2019; Hangartner et al, 2019; Strömblad \& Malmberg, 2016).

As aforementioned, accumulating evidence from previous studies has revealed the ecological (aggregate level) impact of exposure to neighborhood diversity and a negative correlation, especially trust towards others in the local community (Dinesen et al., 2020; van der Meer \& Tolsma, 2014). This negative relationship is often explained by the existence of a perceived economic or cultural threat from outgroups that either compete for scarce resources or introduce cultural practices that threaten the current way of life (Hainmueller and Hopkins, 2014; Hangartner et al, 2019).

Other explanations to the negative correlation between diversity in the local context and trust rely on the human preference for the company of those who are perceived to be similar (homophily). Homophily is sometimes referred to as a residual explanation, as it is assumed from empirical findings where groups of individuals with similar characteristics often form, such as the existence of residential segregation, homogenous friendship networks, and job hiring processes (e.g., Leszczensky \& Pink, 2019; McPherson et al., 2001). When a context is diverse, fewer people may find someone like themselves in that context, thereby inducing withdrawal from social interaction (Putnam, 2007). Ethnic diversity would then make bonds based on (ethnic) similarity more complicated. Diversity is therefore argued to constrict all forms of trust as groups withdraw from social interaction (Putnam, 2007). A key aspect has therefore been to study whether enhanced intergroup contacts that reduce social distances can contribute to higher levels of trust (Dinesen et al., 2020; Pettigrew et al., 2011; Uslaner, 2012).

Recent studies have revealed a more nuanced understanding of the role of intergroup contacts and pointed to the importance of also focusing on where intergroup contacts occur and the experiences that these contacts may elicit (Laurence et al., 2019; Achbari et al., 2021). However, based on the empirical results from previous studies, there are reasons to believe that intergroup contacts that occur in local 
contexts are more strongly correlated with community trust rather than trust in people in general (generalized trust) (Dinesen et al., 2020). Therefore, in the following analyses, we chose to focus on community trust, that is trust towards others in the geographically bounded local community.

Intergroup contacts may also not be of equal importance across all individuals; rather, they may be more salient for individuals that are actually residing in heterogeneous neighborhoods compared with those in homogenous neighborhoods (Gundelach \& Freitag, 2014; Laurence \& Bentley, 2016; Goldschmidt et al., 2017; Laurence et al., 2018). Face-to-face intergroup contact may be a natural part of daily life for those living in diverse neighborhoods and therefore it is possible to also expect that previous experiences of intergroup contacts are more strongly linked to the daily life of those living in diverse neighborhoods.

Another important question is the degree of exposure to intergroup contacts. If intergroup contacts are expected to positively impact community trust, we can assume that the more frequently these contacts occur, the higher the levels of community trust are expected to be (Dinesen et al., 2020). However, previous findings have indicated that intergroup contacts can be moderated by the neighborhood context (Laurence \& Bentley, 2016; Laurence et al., 2018, 2019). By investigating whether neighborhood-level diversity moderates the importance, it is possible to test to what extent intergroup contacts across different contexts are used as a heuristic in the judgment of whether others in the local community are trustworthy. We can expect that the relationship between intergroup contacts and community trust is moderated by neighborhood-level diversity (Laurence et al., 2019; Thomsen et al., 2021). Thus, completely avoiding intergroup contact while living in a diverse neighborhood is likely more strongly linked to social isolation than avoiding intergroup contact while living in a more homogeneous context. Therefore, we proceeded by testing an array of intergroup contacts that may occur in several places, thus providing broader input on the experiences of intergroup contacts of the respondents. The following hypotheses can therefore be formulated:

H1a: Frequent intergroup contacts are more strongly positively correlated with community trust among residents in diverse than homogenous neighborhoods.

H1b: Lack of intergroup contact is more strongly negatively correlated with community trust among residents in diverse than homogenous neighborhoods.

Furthermore, different contexts may differ as to what extent they actually meet the "optimal conditions" of intergroup contacts as posited by Allport (Laurence et al., 2018). The importance of where intergroup contacts take place has also been suggested in previous meta-studies (Pettigrew \& Tropp, 2006). A possible explanation of why the place of the intergroup contacts would matter is that different contexts may also contain different rules and norms on how to behave (Laurence et al., 2018). For instance, schools and workplaces must follow the stipulated regulations, policies, and legislation to prevent threatening or discriminating behavior. Concurrently, studies have shown that discrimination and bullying still exist in schools and workplaces (Laurence et al., 2018). However, for someone who would like to opt out from negative school or workplace contexts, this may require a considerable effort, and it can potentially be costly to change (Laurence et al., 2018). 
Goldschmidt et al. (2017) have shown that intergroup contacts that occur at workplaces do not seem to correlate with community trust (operationalized as trust in neighbors). Other studies have found that intergroup contacts that occur within civil society organizations are more likely to fulfill the optimal conditions posited by Allport and therefore more strongly correlate with generalized trust (Pettigrew \& Tropp, 2006; Achbari et al., 2018) compared with contacts that occur, for instance, in workplaces or at schools (Loxbo, 2018). It has also been suggested that mere exposure to outgroups within neighborhoods is more likely perceived as threatening (Laurence et al., 2018).

Other important locations for intergroup contacts that have been suggested within the literature are schools (e.g., Bentsen, 2021; Loxbo, 2018). As the respondents in the present data set were aged 18 and above, they were most likely to attend secondary (high school or equivalent) or post-secondary (university/college or equivalent) education. In rural or suburban communities, it is common for students to commute to a school or college in a different municipality than where they reside. Similarly, commuting beyond the municipality of residence is common among those belonging to the workforce. The intergroup contacts that occur at school and at work may therefore not automatically be used as heuristics for others within the local community.

Participation in diverse civil society organizations has been found to, under certain conditions, promote tolerance towards outgroups (Pettigrew \& Tropp, 2006; Dahl \& Abdelzadeh, 2017; Achbari et al., 2018; Laurence, 2020), while the connection between intergroup contacts and community trust needs to be further tested. Swedish civil society organizations, in general, tend to have a strong link to local communities and could potentially serve as a heuristic for community trust (Henriksen et al., 2019).

Also, friendships across groups are often considered important to reduce negative sentiments towards other groups (e.g., Christ et al., 2010; Bentsen, 2021). However, it remains unclear to what extent friendships can serve as a heuristic for the local community or whether they mainly are associated with particularized trust (i.e., trust in known others) (Uslaner, 2002, 2012).

Therefore, we investigated whether the impact of intergroup contact varies according to the place where these contacts occur (i.e., school/workplace, neighborhood, civil society, and at home) and across neighborhoods with varying levels of diversity. We assume, based on previous studies (Goldschmidt et al, 2017; Laurence et al., 2018) that if the context where the intergroup contacts occur has a strong link to the local community it will likely correlate positively with community trust, especially for residents in diverse neighborhoods. The following hypotheses were formulated:

H2a: Intergroup contacts that occur in schools/workplaces are not correlated with community trust.

$\mathrm{H} 2 \mathrm{~b}$ : Intergroup contacts that occur in civil society organizations and in neighborhoods are positively correlated with community trust.

$\mathrm{H} 2 \mathrm{c}$ : Intergroup contacts that occur at home are not correlated with community trust. 
H2d: The associations between intergroup contacts that occur in civil society organizations and in neighborhoods with community trust are moderated by neighborhood diversity.

Several studies have argued that different forms of trust are considerably based on experience and that people tend to infer and take cues from intergroup contacts when judging whether other people are trustworthy (Christ et al., 2014). Findings from groups that have migrated to different countries indicate that they under certain conditions tend to adjust to levels of trust in their context of living (Bergh \& Öhrvall, 2018; Dinesen, 2011).

Through experiences, people are likely to develop a heuristic of whether others in their local community are trustworthy or not (Wollebæk et al., 2012; Thomsen et al., 2021). Moreover, it has been argued that some positive experiences from interactions with others are needed for trust to develop (Freitag \& Traunmüller, 2009; Glanville \& Paxton, 2007; Thomsen et al., 2021). Recent studies have shown that negative experiences from intergroup contacts correlated with lower levels of social trust (Thomsen et al., 2021; Achbari et al., 2021). If experiences of intergroup contacts are perceived to be generally negative, these experiences may be generalized to outgroups in general (Fuochi et al., 2020). Studies have shown that the relationship between experiences and trust tends to be asymmetrical, where negative experiences are given more weight and thought to properly reflect the behavior of others in low trust environments (Fetchenhauer \& Dunning, 2010). If people act as if others are not trustworthy, they are also less likely to get proof of the opposite being true as they refrain from trusting behavior (Fetchenhauer \& Dunning, 2010).

Therefore, studies need to consider that individuals may react differently to intergroup contacts, where some react positively and others react negatively (Laurence et al., 2018, 2019). Following results from previous studies (Laurence et al., 2018, 2019), it is likely that community trust is to some extent based on experience. Therefore, we proceed to test whether the sum of positive and negative experiences of intergroup contact are associated with levels of community trust. We posit that sum of experiences from intergroup contacts are especially important for residents in diverse neighborhoods because intergroup contacts are more salient for this group to use as a heuristic for their local community. The term intergroup contact valence is used by Laurence et al., (2018) to tap the overall experiences, negative and positive, from contacts. Therefore, we formulated the following hypothesis:

H3: Intergroup contact valence correlates more strongly with community trust especially among residents in diverse neighborhoods compared to residents in homogeneous neighborhoods.

\section{Data and Method}

The data in the study came from a survey conducted in 2017 with random samples of individuals aged 18-85 years nested within 36 local communities across Sweden. To be eligible for the survey, individuals must have been residents of Sweden for at least 5 years. The 36 municipalities were randomly selected in a two-stage process intended to create a sample with as much variation in contextual-level 
variables as possible within different subgroups of municipalities. From each subgroup, two municipalities were randomly drawn by Statistics Sweden. To these, the three major urban areas (Gothenburg, Malmö, and Stockholm) and the municipality of Piteå were added. The net overall response rate of the survey was slightly below 40\%. On average, around 200 respondents were nested in each municipality. Respondents were also nested at a lower neighborhood (SAMS-district) level within each municipality. The neighborhoods were defined by Statistics Sweden in order to represent actual lived contexts by the residents (Goldschmidt et al., 2017). In total, respondents were nested in 1,263 neighborhoods with varying levels of diversity. The survey (Trustbarometer, 2017) was administered by mail by Statistics Sweden, on behalf of Marie Cederschiöld University College, and self-completed. As trust could be considered the "norm" in the Swedish context, it may be easier for respondents to report low trust in a self-completed anonymous survey.

\section{Dependent Variable}

The dependent variable of the study, community trust was measured with two survey items, which asked respondents "How much or how little do you trust 'the people living in your area' and 'the people living in your municipality" similar to the operationalization used by Wollebaek, Lundåsen, and Trägårdh (2012). The item responses followed a four-point Likert scale, ranging from "do not trust at all" to "trust completely" (scores from 1 to 4 , where 1 equals "do not trust at all" and 4 equals "trust completely"). The correlation between the two items was Pearson's $r=0.59, p<0.000$. An additive index of the two items was created. The index was subsequently rescaled to a $0-100$ index to facilitate the reading of group-level results. The formula [((trust in neighborhood + trust in municipality) -2$) / 6] * 100$ was used to rescale the variable.

\section{Key Independent Variables: Individual Level}

The item that measured the frequency of intergroup contacts was a question included in the survey, similar to the operationalization used by Thomsen et al., (2021), but containing a condition that the intergroup contact included some type of verbal and/ or social interaction. Hence, intergroup contacts as measured in the present study are not merely "mixing". The question was formulated as: "How often do you interact with or talk to someone with a background in a different country than yourself... [followed by a list] at home, at school/work; in the neighborhood; in a civil society organization?". The items used a five-point scale: several times a week, once a week, a few times a month, more seldom, and never. The scale used varied from 0 (never) to 4 (several times a week). In order to tap the overall level of intergroup contacts across the four different places (home, school/work, neighborhood, and in civil society organizations), an additive index was constructed. The index ranged from 0 (no contact at all in any place) to 16 (contacts several times a week across all places), and the Cronbach's alpha of the additive index was 0.66 . 
Contact valence was tapped using the following three survey items: "Generally speaking, do you consider contacts with people from a different country than yourself [and a list with: within school/workplace; within neighborhood; within civil society organizations] as positive or negative?". The question contained an explanation indicating that that the contacts were not limited to friends but included interactions with people in general. Each item had a four-point Likert scale: very positive (3), rather positive (2), rather negative (1), and very negative (0). No contact valence question was asked for contacts that took place at home. An additive index (0-9) was constructed that contained all of the three contact valence items, where 0 equaled very negative views across all three places of intergroup contacts and 9 equaled very positive views across all three places (Cronbach's alpha $=0.93$ ). Respondents that did not report any intergroup contacts across any of the places were coded as missing in the contact valence index.

\section{Key Independent Variable: Neighborhood Level}

Diversity at the neighborhood level was measured as the share (percent) of residents that are born in regions that in other studies (Loxbo, 2018; Strömblad \& Malmberg, 2016) have been associated with being a visible minority in Sweden. The presence of visible minorities is used as a proxy for the share of diversity within the neighborhood (Loxbo, 2018; Strömblad \& Malmberg, 2016). The group of visible minorities is operationalized, in line with previous studies (Strömblad \& Malmberg 2016), as the share of the population that are first-generation immigrants from countries within the MENA region (i.e., Middle East and North Africa) and Sub-Saharan African countries. Consistent with what previous studies have shown (Strömblad \& Malmberg, 2016), a common trait across the most diverse neighborhoods was that they have a lower share of residents who are natives. The correlation between the share of native Swedes and presence of visible minorities in the sampled neighborhoods was very strong (Pearson's $r=-0.88, p<0.000$ ). The presence of visible minorities across the sample of neighborhoods ranged from 0 to $45 \%$ (mean value of 4.14 , standard deviation of 6.57 , median $6 \%$ ).

\section{Control Variables}

In the multilevel analyses, at the individual level, we controlled for demographic variables, such as age (dividing the sample into four different age groups), gender (women as the reference group), and Swedish or immigrant background (immigrant background as reference group). Also, the individual levels of education and income were controlled for. Studies have argued for the importance of controlling for personality traits (the so-called Big Five) to create robust models that control for other types of prosocial values (van Ingen \& Bekkers, 2015; Ackermann 2019). These personality traits may also be correlated with the respondents' willingness to engage in intergroup contacts. The five main personality traits used in the models were openness, neuroticism/stability, agreeableness, extraversion, and conscientiousness. 
At the neighborhood and municipality levels, we also controlled for aggregate socioeconomic and demographic variables. We controlled for the level of net income within neighborhoods. The mean income across all the surveyed neighborhoods was $262,510 \mathrm{SEK} /$ annual income (with a standard deviation of 72,065). The mean individual net income of Sweden as a whole was 278,900 SEK/annual incomes in 2017, showing that the sample mean was quite close to the national-level mean. The minimum net income within a neighborhood was 91,095 SEK/annual incomes, and the maximum net income was $984,608 \mathrm{SEK} /$ annual income. At the municipality level in the multilevel analyses, we controlled for population size, income inequality (Gini index, coded 0 to 1 , where 0 means perfect equality of incomes and 1 means that all incomes are concentrated to one individual within the municipality), and homogeneity of the population (Herfindahl index, normalized, coded 0 to 1 where 0 equals perfect heterogeneity and 1 equals perfect homogeneity, i.e., all residents have backgrounds in the same country). Municipal income inequality and diversity have been found in previous studies to correlate with individual levels of community trust (Wallman Lundåsen \& Wollebæk, 2013). Descriptive statistics for all variables are shown in Table 1.

\section{Models}

Given the nested structure of the data, with respondents nested both in neighborhoods and municipalities mixed linear models were used to analyze the data. The intra-class correlation of community trust in an empty model corresponds to 0.03 at the municipality level and 0.06 at the neighborhood level. Following Barr et al., (2013) and Schmidt-Catran and Fairbrother, (2016), models that contain both random slopes and random intercepts are used. In the analyses, municipality level diversity (homogeneity) and neighborhood level diversity were modelled as random effects.

\section{Results}

We analyzed the data using mixed linear models with three levels, individuals, neighborhoods, and municipalities, and we allowed for both random intercepts and slopes (according to diversity both at the municipality and neighborhood levels). We proceeded with testing $\mathrm{H} 1 \mathrm{a}$ and $\mathrm{H} 1 \mathrm{~b}$. We interacted the level of neighborhood diversity with the intergroup contact index (i.e., contacts at home, at school/workplace, in the neighborhood, and in civil society organizations). As interactions may be hard to interpret across the whole range of neighborhood diversity, the margins with predicted values for the respondents nested in neighborhoods with no diversity, median level diversity and 95th percentile diversity, are presented as separate lines in Fig. 1. The results show that those with no intergroup contact whatsoever (Fig. 1) consistently have lower levels of community trust independent of the share of diversity within their neighborhood. 


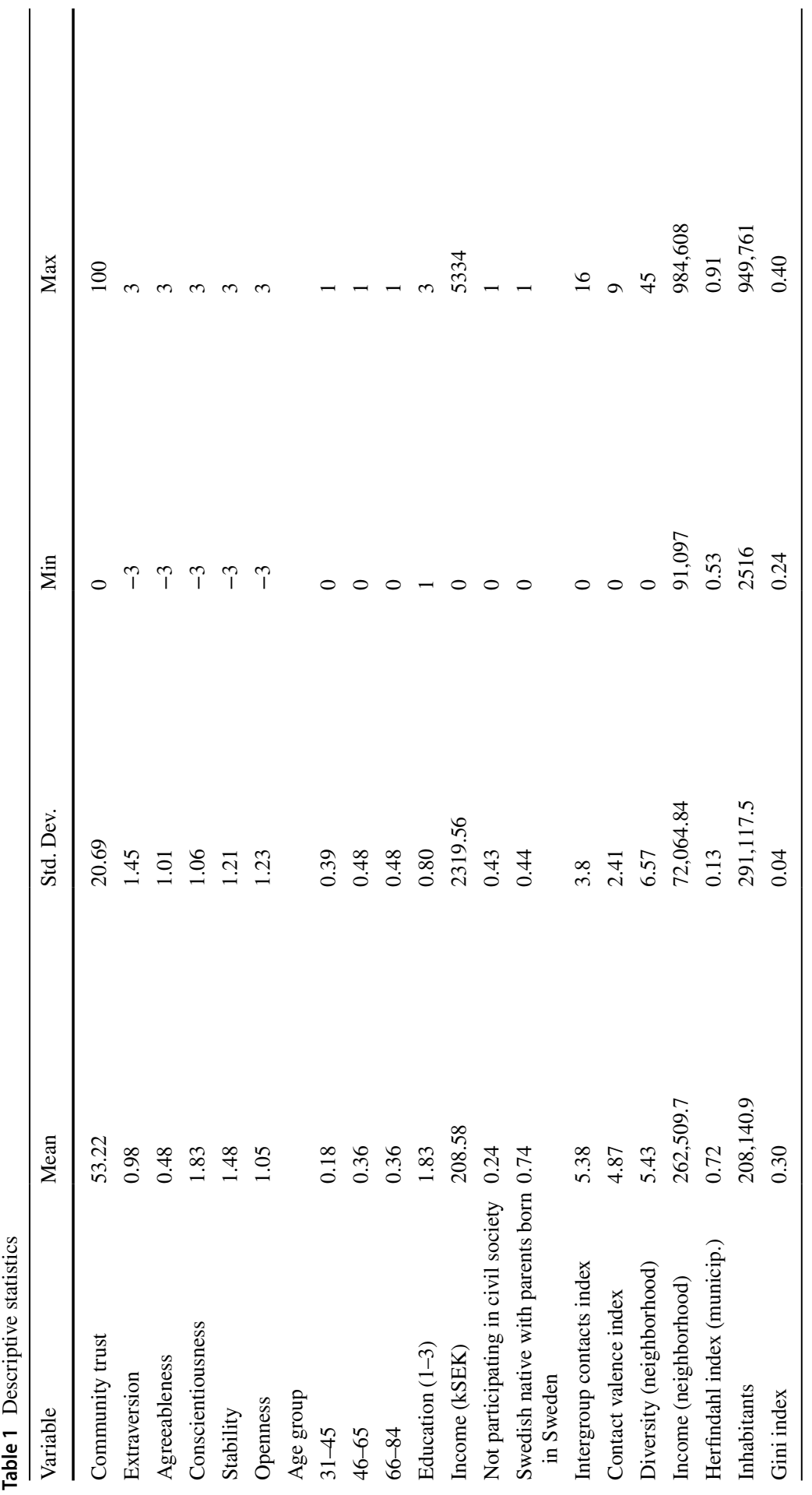




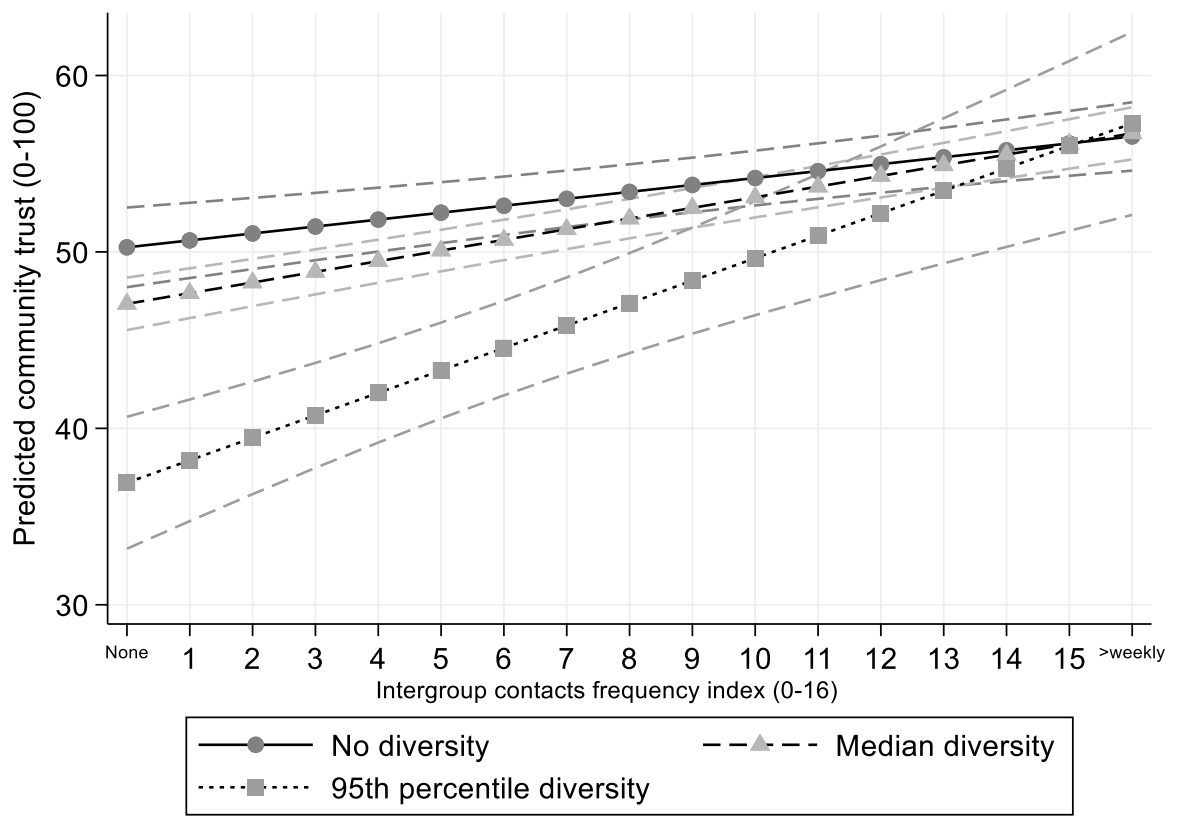

Fig. 1 Intergroup contacts and diversity, 95\% confidence intervals. Note: Predictive margins according to different levels of diversity. Using Table 2, model 1

The results from the mixed model (Fig. 1, using Table 2, model 1) show that the group residing in the most diverse neighborhoods have the steepest slope, indicating that intergroup contacts tend to go hand in hand with a larger increase in community trust among residents in the most diverse neighborhoods. As an example, if someone residing in the most diverse neighborhood (95th percentile) were to have no intergroup contacts, their level of community trust would on average correspond to around 41 on the $0-100$ community trust index. If the same individual were to, instead, have the highest frequency of intergroup contact, this would correspond to a score of community trust of slightly less than 59 on the $0-100$ community trust index, all else being equal. The difference equals a $44 \%$ increase in community trust and is clearly non-negligible. At the maximum value of the intergroup contact index, there is no difference in community trust across the different levels of neighborhood diversity. However, it is worth noting that the most substantial impact on community trust from intergroup contacts on is expected to occur above the median value of the frequency of contacts' index. Clearly, H1a and H1b find support in our data.

We then proceed to test $\mathrm{H} 2 \mathrm{a}, \mathrm{H} 2 \mathrm{~b}$, and $\mathrm{H} 2 \mathrm{c}$ to determine whether intergroup contacts that occur in specific places with connections to the local context more strongly correlate with community trust (Table 2, model 2). First it is important to note that the intergroup contacts occur at varying degrees across the four different surveyed contexts. Having intergroup contacts at home indicates having a closer relationship, and these experiences may not automatically transfer into trust in others in the local community. A clear majority of the respondents (about $72 \%$ ) never or 
Table 2 Intergroup contacts, neighborhood diversity, and community trust as dependent variable, mixed models, unstandardized fixed effects coefficients, robust standard errors in parentheses

\begin{tabular}{|c|c|c|}
\hline & Model 1 & Model 2 \\
\hline Extraversion & $\begin{array}{l}0.83^{* * * *} \\
(0.20)\end{array}$ & $\begin{array}{l}0.76^{* * *} \\
(0.22)\end{array}$ \\
\hline Agreeableness & $\begin{array}{l}2.13 * * * \\
(0.19)\end{array}$ & $\begin{array}{l}2.28 * * * \\
(0.21)\end{array}$ \\
\hline Conscientious & $\begin{array}{l}-1.14^{* * * *} \\
(0.20)\end{array}$ & $\begin{array}{l}-1.08 * * * \\
(0.20)\end{array}$ \\
\hline Stability & $\begin{array}{l}1.53 * * * \\
(0.20)\end{array}$ & $\begin{array}{l}1.50 * * * \\
(0.28)\end{array}$ \\
\hline Openness & $\begin{array}{l}0.23 \\
(0.28)\end{array}$ & $\begin{array}{l}0.44 \\
(0.28)\end{array}$ \\
\hline \multicolumn{3}{|l|}{ Age (18-30 years as ref.) } \\
\hline $31-45$ & $\begin{array}{l}1.61 \\
(0.98)\end{array}$ & $\begin{array}{l}1.55^{* *} \\
(1.00)\end{array}$ \\
\hline $46-65$ & $\begin{array}{l}5.20 * * \\
(1.50)\end{array}$ & $\begin{array}{l}5.09^{* *} \\
(1.54)\end{array}$ \\
\hline $66-85$ & $\begin{array}{l}10.02 * * * \\
(1.53)\end{array}$ & $\begin{array}{l}9.14 * * * \\
(1.54)\end{array}$ \\
\hline \multicolumn{3}{|l|}{ Education (Primary as ref.) } \\
\hline Secondary & $\begin{array}{l}1.98^{* *} \\
(0.57)\end{array}$ & $\begin{array}{l}1.94 * * \\
(0.68)\end{array}$ \\
\hline Tertiary & $\begin{array}{l}4.70 * * * \\
(0.68)\end{array}$ & $\begin{array}{l}4.98 * * * \\
(0.73)\end{array}$ \\
\hline Income & $\begin{array}{l}0.00 \\
(0.00)\end{array}$ & $\begin{array}{l}0.00 \\
(0.00)\end{array}$ \\
\hline No civil society & $\begin{array}{l}-3.94 * * * \\
(0.63)\end{array}$ & $\begin{array}{l}-3.73 \text { *** } \\
(0.60)\end{array}$ \\
\hline Swedish & $\begin{array}{l}3.45^{* * * *} \\
(0.67)\end{array}$ & $\begin{array}{l}3.19 * * * \\
(0.71)\end{array}$ \\
\hline \multicolumn{3}{|l|}{ Municipality level } \\
\hline Diversity (Herfindahl) & $\begin{array}{l}15.48^{*} \\
(6.38)\end{array}$ & $\begin{array}{l}15.50 * \\
(6.61)\end{array}$ \\
\hline Population size & $\begin{array}{l}0.00 \\
(0.00)\end{array}$ & $\begin{array}{l}0.00 \\
(0.00)\end{array}$ \\
\hline Inequality (gini) & $\begin{array}{l}-44.58^{* *} \\
(14.98)\end{array}$ & $\begin{array}{l}-44.85^{* *} \\
(14.49)\end{array}$ \\
\hline \multicolumn{3}{|l|}{ Neighborhood level } \\
\hline Income & $\begin{array}{l}0.00^{* *} \\
(0.00)\end{array}$ & $\begin{array}{l}0.00^{* * *} \\
(0.00)\end{array}$ \\
\hline \multicolumn{3}{|l|}{ Cross-level interaction } \\
\hline Intergroup contacts index & $\begin{array}{l}0.39 * * * \\
(0.09)\end{array}$ & \\
\hline
\end{tabular}


Table 2 (continued)

\begin{tabular}{|c|c|c|}
\hline & Model 1 & Model 2 \\
\hline Contacts: at home & & $\begin{array}{l}0.37 \\
(0.22)\end{array}$ \\
\hline Contacts: school/work & & $\begin{array}{l}0.23 \\
(0.24)\end{array}$ \\
\hline Contacts: neighborhood & & $\begin{array}{l}0.95 * * * \\
(0.27)\end{array}$ \\
\hline Contacts: civil society & & $\begin{array}{l}0.82 * * \\
(0.25)\end{array}$ \\
\hline Diversity (neighborhood) & $\begin{array}{l}-0.53^{* * * *} \\
(0.01)\end{array}$ & $\begin{array}{l}-0.32 * * * \\
(0.06)\end{array}$ \\
\hline Intergroup contacts index $\times$ Diversity & $\begin{array}{l}0.03 * * \\
(0.01)\end{array}$ & \\
\hline $\mathrm{AIC} / \mathrm{BIC}$ & $54,756.26 / 54931.73$ & $50,522.51 / 50709.23$ \\
\hline$N$ (individuals/neighborhoods/municipalities) & $6,305 / 1,267 / 36$ & $5,817 / 1,241 / 36$ \\
\hline
\end{tabular}

Note: Constants omitted

seldom reported having intergroup contacts in their homes, while around $60 \%$ of the respondents reported having had recurring intergroup contacts at their workplaces or schools. Around $40 \%$ reported having had recurring intergroup contacts within their neighborhoods, and around 30\% within civil society organizations. There are only small direct correlations between the frequency of intergroup contacts in the different contexts and levels of neighborhood diversity (see Table 4). Intergroup contacts within the neighborhood and neighborhood diversity display the largest direct correlation (Pearson's $r=0.2, p<0.000$ ) albeit it must be considered as a weak correlation.

We proceed by running mixed models with intergroup contacts that occur in different places entered as separate variables. The results show that there are differences in their direct correlations with community trust according to the places in which the contacts occur. Intergroup contacts that occur within civil society organizations and in neighborhoods have a statistically significant correlation with community trust when all different contacts are considered simultaneously. Intergroup contacts that occur within schools/workplaces and in the more intimate sphere of the home lack a direct overall significant association with community trust. H2a, H2b, and H2c, therefore, found support in our data (Fig. 2) (Table 2, model 2).

To test differences according to levels of neighborhood diversity, we proceed by testing $\mathrm{H} 2 \mathrm{~d}$ by introducing the interaction effect between intergroup contacts in neighborhoods and in civil society organizations, and neighborhood diversity (Table 3). The analyses also show that residents in the most diverse neighborhoods have similar levels of community trust to residents in the most homogenous neighborhoods if they have very frequent intergroup contact with people in their neighborhood. The benefits of frequent intergroup contact are therefore higher among residents in the most diverse neighborhoods. All things being equal, the difference between never having any intergroup contacts and having 
Fig. 2 Frequency of intergroup contacts in different places, community trust as dependent variable, point estimates regression coefficients (95\% confidence intervals). Note: Table 2, using model 2. Circles represent point estimates of regression coefficients, lines $95 \%$ confidence intervals

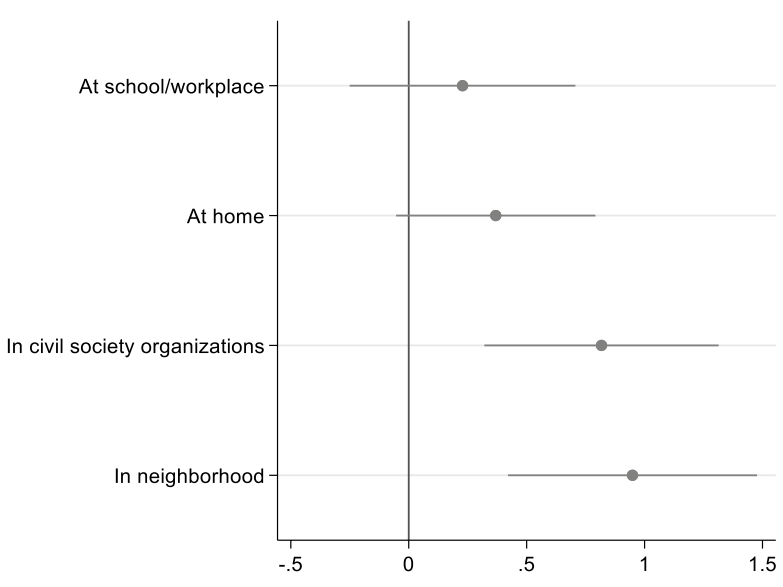

frequent (several times a week) contacts regarding community trust is expected to be about 14 points (on a 0-100 index scale). The difference is striking (Fig. 3).

Thereafter, we test the interaction between neighborhood diversity and intergroup contacts in civil society organizations and community trust. Figure 4 reveals that those lacking intergroup contacts in civil society consistently had lower levels of community trust across all levels of neighborhood diversity. Residents in the most diverse neighborhoods were predicted to have higher levels of community trust with more frequent intergroup contacts. Among those who reported the most frequent intergroup contacts in civil society organizations, the predicted levels of community trust were similar, irrespective of their neighborhood diversity. However, intergroup contacts in civil society organizations that occur more often than monthly only limitedly impact levels of community trust among residents in more homogenous neighborhoods (Fig. 4).

Overall, respondents without intergroup contacts consistently had lower levels of community trust than those with very frequent intergroup contacts. The results showed that residents in the most diverse neighborhoods who had the most frequent intergroup contacts tended to have markedly higher levels of community trust than those with less frequent intergroup contacts, while the difference among those who have intergroup contacts in the neighborhood and in civil society organizations was predicted to be considerably smaller among those who lived in the more homogeneous neighborhoods. H2d support in our data, as intergroup contacts in the neighborhoods and in civil society organizations were moderated by neighborhood diversity.

Hypothesis 3 posited that the overall experiences (negative or positive), that is, the contact valence, from intergroup contacts to be associated with community trust. Even though it is not possible to rule out the fact that those who have positive feelings towards diversity self-select into diverse neighborhoods, the analyses show that there is little evidence of any direct correlation between the contact valence index and neighborhood diversity (Table 4 ). We proceed by running a mixed model that 


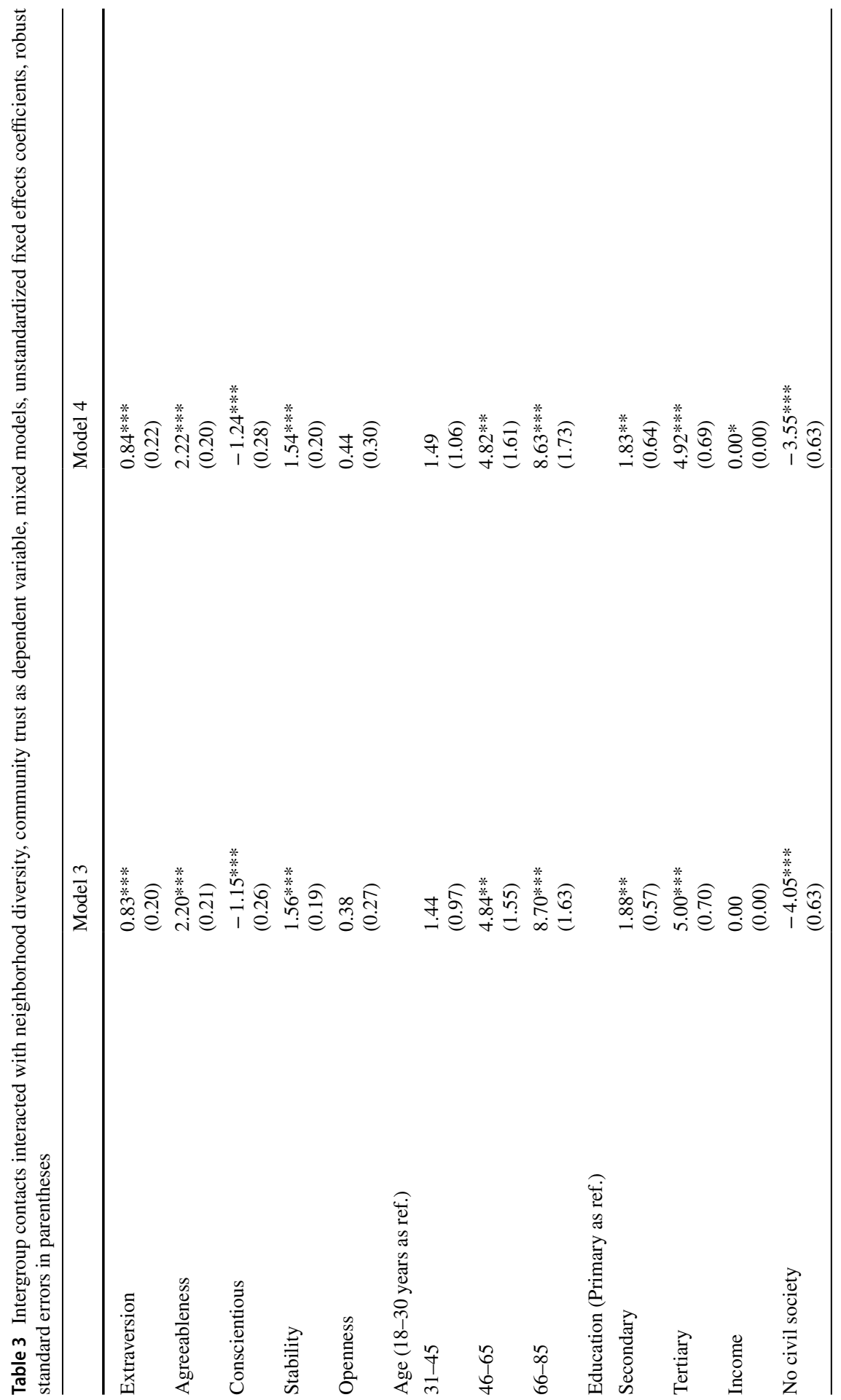




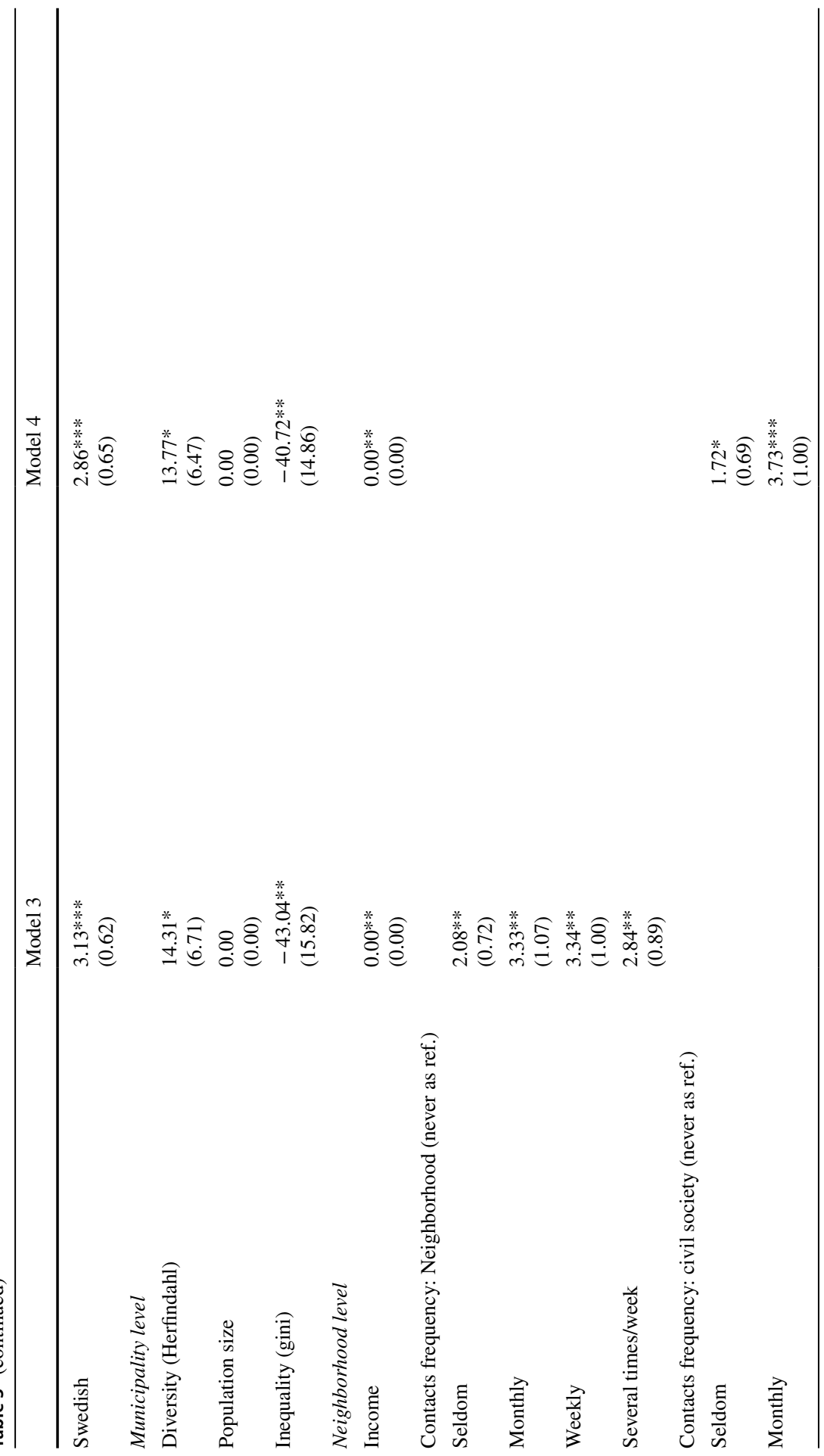




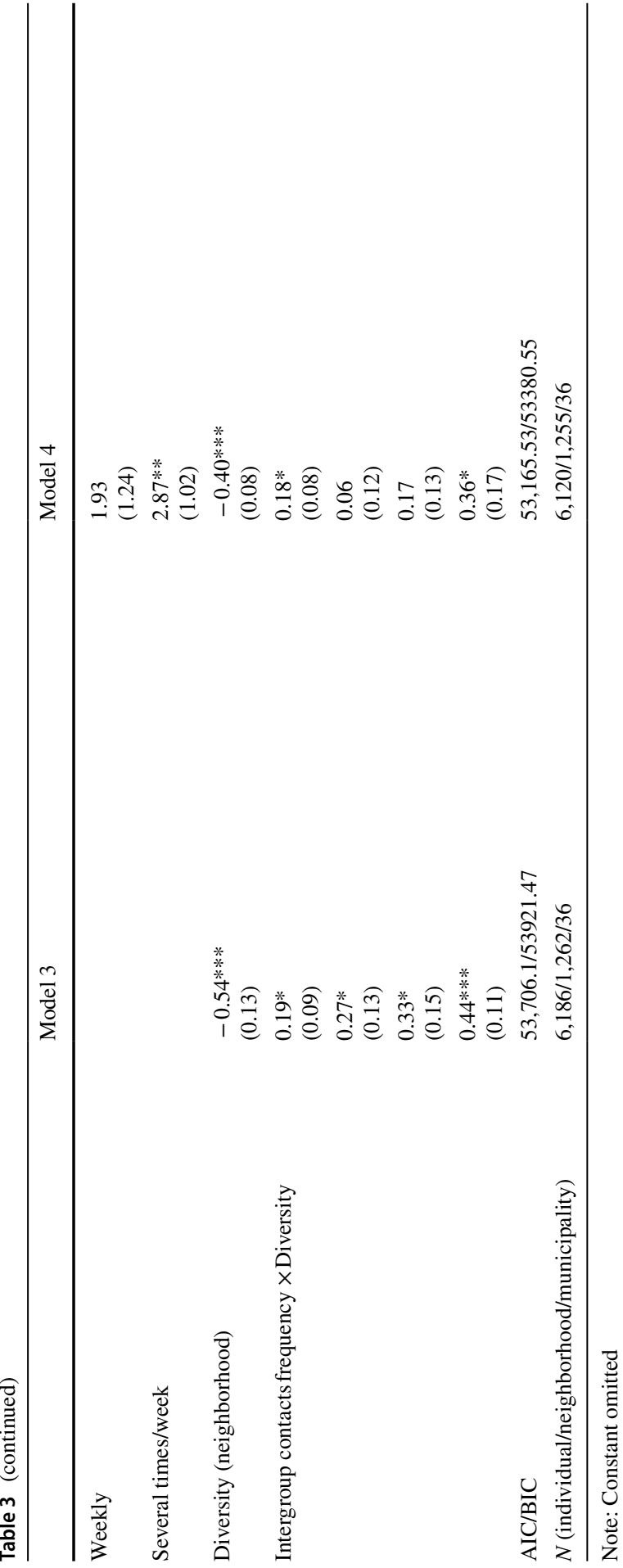




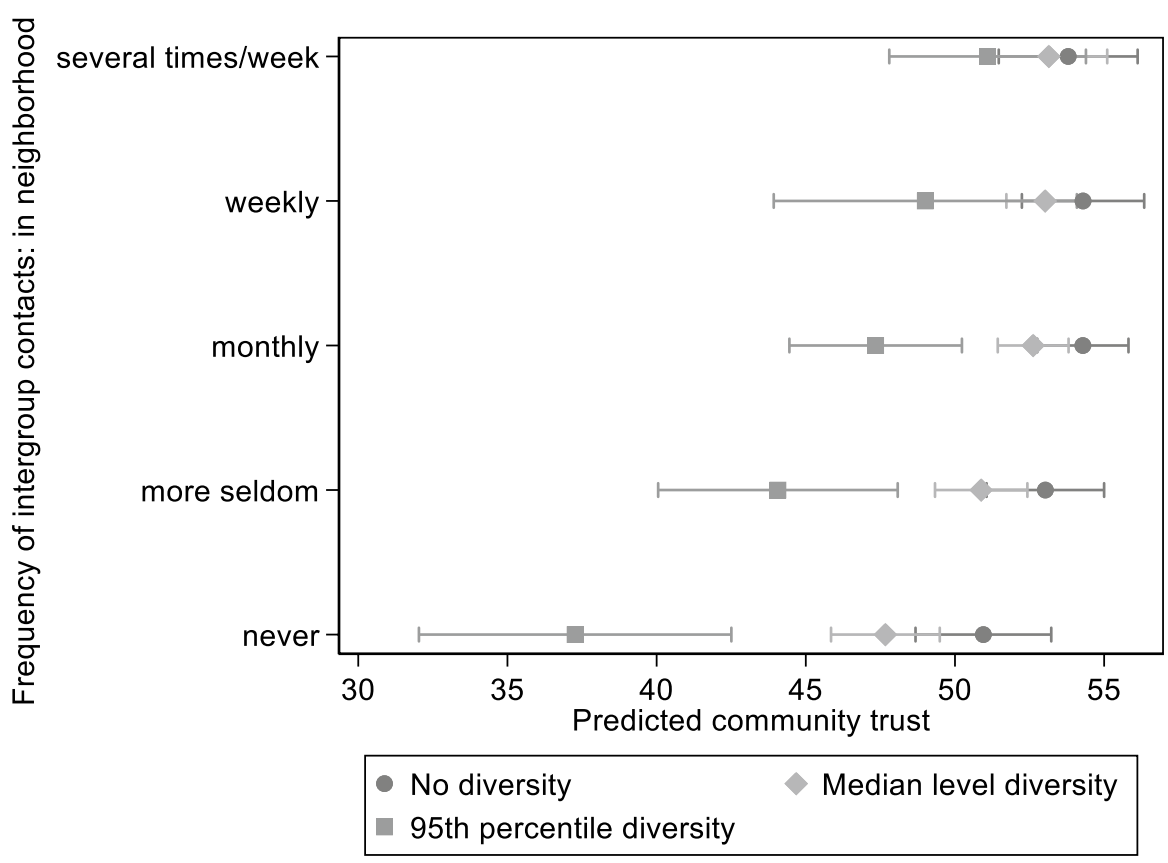

Fig. 3 Intergroup contacts in the neighborhood according to levels of diversity, community trust as dependent variable, predictive margins, $95 \%$ confidence intervals. Note: Predictive margins according to different levels of diversity. Table 3, using model 3

interacts the contact valence index with neighborhood diversity. The overall coefficient of the interaction is positive and statistically significant (Table 5). However, one notable finding that becomes apparent in Fig 5 is that those with the most positive contact valence index are indifferent to the share of diversity within their neighborhood in their judgment of whether others in the local community are trustworthy.

The levels of community trust of those that are very positive to all intergroup contacts are high and practically invariant, irrespective of the level of diversity in their neighborhood. Thus, the results indicate that positive contact valence does not moderate the association between of diversity and community trust among the respondents with the highest score on the contact valence index. The middle group, which consists of those who have a neutral contact valence (i.e., neither positive nor negative), is predicted to have slightly decreasing levels of community trust with increasing diversity in their neighborhoods of residence. The group with the most negative views on intergroup contacts on the other hand has the steepest negative slope compared with the other two groups meaning that with increasing levels of neighborhood diversity community trust is expected to decrease more sharply among those who perceive intergroup contacts to be very negative. Thus, the results display an increasing distance in community trust levels with increasing levels of diversity according to perceptions of intergroup contacts. The results can be interpreted as an indication of an asymmetry between positive and negative contact 


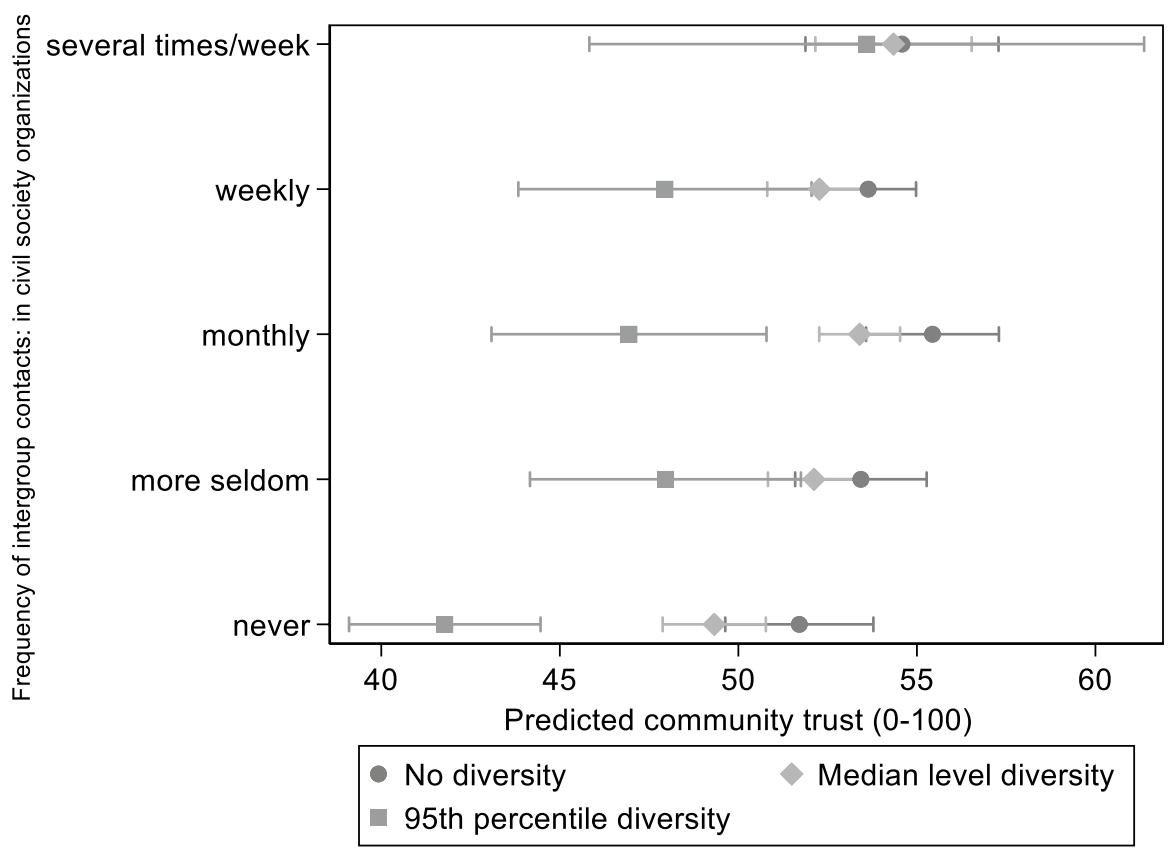

Fig. 4 Intergroup contacts in the neighborhood according to levels of diversity, community trust as dependent variable, predictive margins, $95 \%$ confidence intervals. Note: Predictive margins according to different levels of diversity. Table 3 , using model 4

valence (Fetchenhauer \& Dunning, 2010). Positive contact valence does not seem to counterbalance negative contact valence in diverse contexts (Fig. 5).

Therefore, the results can only partly corroborate $\mathrm{H} 3$, as only very negative or neutral contact valence were moderated by neighborhood diversity levels.

\section{Conclusions}

This study has contributed with insights on the association between different instances of intergroup contacts, neighborhood diversity, and community trust, using a large-scale survey from a highly trusting society with a recent history of

Table 4 Correlation matrix, intergroup contacts, and neighborhood level diversity, pairwise correlations (Pearson's r)

\begin{tabular}{ll}
\hline & $\begin{array}{l}\text { Neigh- } \\
\text { borhood } \\
\text { diversity }\end{array}$ \\
\hline Contacts: at home & $0.11^{* * *}$ \\
Contacts: school/workplace & $0.01^{* *}$ \\
Contacts: neighborhood & $0.23^{* * *}$ \\
Contacts: civil society & 0.00 \\
Contact valence index & 0.01 \\
\hline$* *$
\end{tabular}


Table 5 Contact valence, interacted with neighborhood diversity, community trust as dependent variable, mixed model, unstandardized fixed effects coefficients, robust standard errors in parentheses

Model 5

Extraversion

Agreeableness

Conscientious

Stability

Openness

$0.60 * *$

(0.22)

$1.71 * * *$

(0.18)

$-1.08 * * *$

$(0.24)$

$1.56 * * *$

$(0.22)$

$0.18(0.29)$

Age (18-30 years as ref.)

31-45

$2.22 *$

(0.91)

46-65

$6.23 * *$

(1.33)

66-85

$11.16 * * *$

(1.17)

Education (low as ref.)

Secondary

Tertiary

$1.45 * *$

(0.61)

$3.46 * * *$

$(0.75)$

Income

No civil society

Swedish

0.00

(0.00)

$-3.02 * * *$

(0.63)

$3.92 * * *$

(0.63)

Municipality level

Diversity (Herfindahl)

$15.32 * *$

(5.76)

Population size

0.00

(0.00)

Inequality (gini)

Neighborhood level

Income

$0.00 *$

(0.00)

Cross-level interaction

Contact valence index

$1.51 * * *$

(0.22)

0.00

(0.09)

Diversity (neighborhood)

$-0.55 * * *$

(0.10)

$0.06 * *$

(0.02)

AIC/BIC

46,519.29/46697.28

$5,390 / 1,228 / 36$

$N$ (individuals/neighborhoods/municipalities)

Note: Constant omitted 


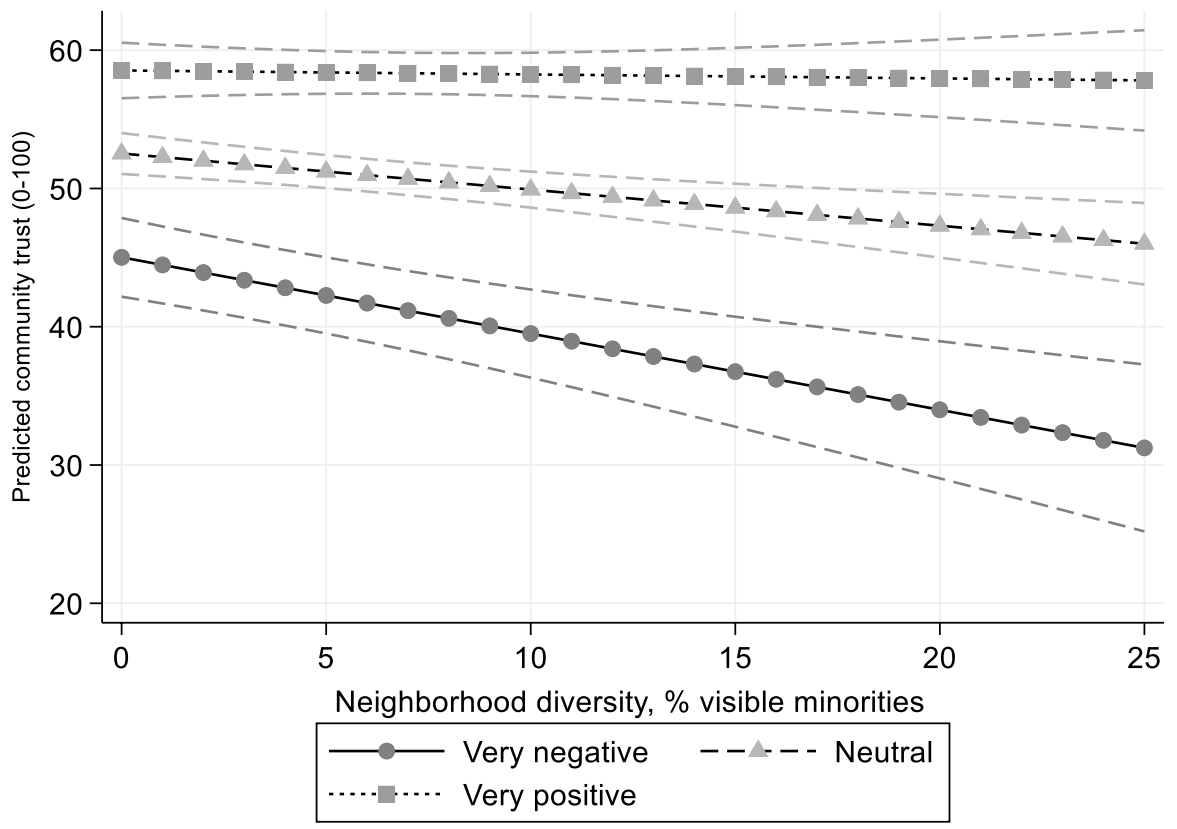

Fig. 5 Contact valence index and neighborhood diversity, predictive margins, $95 \%$ confidence intervals. Note: Predictive margins according to different levels of diversity. Table 5, using model 5, the figure displays estimates for those with maximum (9), medium (5), and lowest (0) scores on the contact valence index. Results for all scores shown in the supplemental file

rapidly increasing diversity. As already stated above, Sweden could be considered as a tough empirical test given the generally high levels of trust. The results from the present study add to previous findings (Laurence, 2020; Laurence \& Bentley, 2016) by taking a more holistic view on intergroup contacts and moves beyond focusing on single places or instances (Bentsen, 2021; Loxbo, 2018) where intergroup contacts may occur. Community trust is an important collective resource as it can explain the willingness to cooperate to solve problems within the local community (Wollebæk et al., 2012).

The findings indicate that frequent intergroup contacts are more strongly associated with community trust among respondents who are residents in diverse (i.e., presence of visible minorities) neighborhoods. The results also show that those who refrain from intergroup contact and concurrently reside in diverse neighborhoods are far less likely to trust others in their local community. Not having any or only minimal interaction with outgroups likely increases the possibility to maintain or even reinforce negative preconceptions about others (Stolle et al., 2008; Wallman Lundåsen \& Wollebæk, 2013; Thomsen et al., 2021).As the analyses are based on cross-sectional data it is not possible to infer causality; however, refraining from intergroup contacts while living in a diverse neighborhood is likely a stronger indication of segregation and sense of anomie than for those residing in more homogeneous neighborhoods. Moreover, there was no evidence of a strong direct correlation between neighborhood diversity and the frequency of intergroup contacts. The 
absence of a strong direct correlation is an indicator of the fact that also those who live in diverse neighborhoods are socializing to a great extent with their ingroup.

The results also indicate that certain intergroup contacts like those that take place in the neighborhood of residence and in civil society organizations had a stronger positive association with community trust than intergroup contacts that took place in schools/workplaces or at home. Having intergroup acquaintances in the neighborhood seems to contribute the most to higher levels of community trust. A possible interpretation of these findings is that intergroup contacts in neighborhoods and in civil society organizations more easily are used as a heuristic of whether to trust in others in the specific local community or not. A potential caveat with these findings is, however, that those places where intergroup contacts tended to occur most frequently, such as in schools and workplaces, had no statistically significant relation with community trust. This finding lends support to previous studies (Goldschmidt et al., 2017). A possible explanation of the null finding is that schools/workplaces may be located elsewhere (as people can commute to schools and workplaces) and are therefore less likely to be used as a heuristic for whether others in the local community are to be trusted or not.

However, the results also showed that just using the mere frequency of intergroup contacts is not sufficient to understand its association with community trust. We also must consider how these intergroup contacts are perceived to understand their associations with community trust. A large share of the respondents perceives intergroup contacts to be overall positive, but some respondents perceive intergroup contacts as negative. With a negative view of experiences from intergroup contacts, these are unlikely to be positively associated with community trust. The analyses showed that the overall evaluation of different intergroup contacts was associated with community trust, in line with previous findings from other country contexts (Laurence \& Bentley, 2016; Thomsen et al., 2021). The results however indicated an asymmetrical association, and respondents with very positive evaluations (positive contact valence) of intergroup contacts were not estimated to have higher levels of community trust with increasing neighborhood diversity, also indicating a possible ceiling effect.

Community trust among those in the most positive group was therefore not moderated by neighborhood diversity, whereas community trust especially among the most negative group was moderated by neighborhood diversity. These findings suggest that those with either neutral or pessimistic overall contact valence tended to drive the overall negative association between neighborhood diversity and community trust. These results also point to the fact that there may be an asymmetry between the relative importance of negative and positive experiences especially in diverse neighborhoods (Fetchenhauer \& Dunning, 2010). Diversity moderates negative contact valence and reinforces distrust in highly diverse neighborhoods, while neighborhood diversity does not appear to moderate very positive contact valence. Important avenues for future studies are to further investigate the mechanisms that drive the asymmetry between negative and positive experiences from intergroup contacts especially for residents in diverse neighborhoods. 
Supplementary Information The online version contains supplementary material available at https://doi. org/10.1007/s12134-021-00932-z.

Acknowledgements This research was made possible through generous access to the survey the Trustbarometer. The Trustbarometer is carried out by Statistics Sweden on behalf of Marie Cederschiöld University College (previously named Ersta Sköndal Bräcke University College) and is financed by Länsförsäkringars forskningsfond. PI for the Trustbarometer is Professor Lars Trägårdh at the Center for Civil Society Research at Marie Cederschiöld University College, Sweden. Susanne Wallman Lundåsen is also affiliated to the Center for Civil Society Research, Marie Cederschiöld University College. The author is grateful for comments received during a research seminar at the Centre for Local Government Studies, Linköping University.

Funding Open access funding provided by Linköping University. Länsförsäkringars forskningsfond's grant for the Trustbarometer (2017) and the grant 'Mötesplats för mångfald" eller "Lika barn leka bäst"?' from the Swedish Agency for Youth and Civil Society.

Availability of Data and Material Data is not possible to deposit due to Swedish regulations of data protection and privacy of respondents.

\section{Declarations}

Conflict of Interest The authors declare no competing interests.

Open Access This article is licensed under a Creative Commons Attribution 4.0 International License, which permits use, sharing, adaptation, distribution and reproduction in any medium or format, as long as you give appropriate credit to the original author(s) and the source, provide a link to the Creative Commons licence, and indicate if changes were made. The images or other third party material in this article are included in the article's Creative Commons licence, unless indicated otherwise in a credit line to the material. If material is not included in the article's Creative Commons licence and your intended use is not permitted by statutory regulation or exceeds the permitted use, you will need to obtain permission directly from the copyright holder. To view a copy of this licence, visit http://creativecommons.org/licen ses/by/4.0/.

\section{References}

Achbari, W., Gesthuizen, M., \& Holm, J. (2018). Ethnic diversity and generalized trust: Testing the contact hypothesis in Dutch voluntary organizations. Nonprofit and Voluntary Sector Quarterly, 47(4), 813-835.

Achbari, W., Geys, B., \& Doosje, B. (2021). Comparing the effect of cross-group friendship on generalized trust to its effect on prejudice: The mediating role of threat perceptions and negative affect. PloS one, 16(2), e0245983.

Allport, G. (1954). The nature of prejudice. Addison-Wesley.

Barr, D. J., Levy, R., Scheepers, C., \& Tilly, H. J. (2013). Random effects structure for confirmatory hypothesis testing: Keep it maximal. Journal of Memory and Language, 68, 255-278.

Bentsen, B.M.A. (2021). Intergroup contact and negative attitudes towards immigrants among youth in Sweden: Individual and contextual factors. Journal of International Migration \& Integration.

Bergh, A., \& Öhrvall, R. (2018). A sticky trait: Social trust among Swedish expatriates in countries with varying institutional quality. Journal of Comparative Economics, 46(4), 1146-1157.

Christ, O., Hewstone, M., Tausch, N., Wagner, U., Voci, A., Hughes, J., \& Cairns, E. (2010). Direct contact as a moderator of extended contact effects: Cross-sectional and longitudinal impact on outgroup attitudes behavioral intentions and attitude certainty. Personality and Social Psychology Bulletin, 36(12), 1662-1674. https://doi.org/10.1177/0146167210386969 
Christ, O., Schmid, K., Lolliot, S., Swart, H., Stolle, D., Tausch, N., ... \& Hewstone, M. (2014). Contextual effect of positive inter-group contact on outgroup prejudice. Proceedings of the National Academy of Sciences, 111(11), 3996-4000.

Delhey, J., \& Newton, K. (2005). Predicting cross-national levels of social trust: Global pattern or nordic exceptionalism? European Sociological Review, 21(4), 311-327. https://doi.org/10.1093/esr/jci022

Delhey, J., Newton, K., \& Welzel, C. (2011). How general is trust in "most people"? Solving the radius of trust problem. American Sociological Review, 76(5), 786-807.

Dahl, V., \& Abdelzadeh, A. (2017). Self-selection or socialization? The longitudinal relation between civic engagement and political orientations among adolescents. Nonprofit and Voluntary Sector Quarterly, 46(6), 1250-1269. https://doi.org/10.1177/0899764017728363

Dinas, E., Matakos, K., Xefteris, D., \& Hangartner, D. (2019). Waking up the golden dawn: Does exposure to the refugee crisis increase support for extreme-right parties? Political Analysis, 27(2), 244-254.

Dinesen, P. T. (2011). Me and Jasmina down by the schoolyard: An analysis of the impact of ethnic diversity in school on the trust of schoolchildren. Social Science Research, 40(2), 572-585.

Dinesen, P. T., Schaeffer, M., \& Sønderskov, K. M. (2020). Ethnic diversity and social trust: A narrative and meta-analytical review. Annual Review of Political Science, 23(1), 441-465.

European Values Study/World Values Survey Joint EVS/WVS 2017-2021 data set (EVS/WVS). (2021) https://doi.org/10.4232/1.13670

Fetchenhauer, D., \& Dunning, D. (2010). Why so cynical? Asymmetric feedback underlies misguided skepticism regarding the trustworthiness of others. Psychological Science, 21(2), 189-193.

Finseraas, H., Hanson, T., Johnsen, A. A., Kotsadam, A., \& Torsvik, G. (2019). Trust, ethnic diversity, and personal contact: A field experiment. Journal of Public Economics, 173, 72-84.

Freitag, M., \& Traunmüller, R. (2009). Spheres of trust: An empirical analysis of the foundations of particularised and generalised trust. European Journal of Political Research, 48(6), 782-803.

Fuochi, G., Voci, A., Boin, J., \& Hewstone, M. (2020). Affective generalization from intergroup contact: Associations between contact-related and outgroup-related empathy, anxiety, and trust. Group Processes \& Intergroup Relations, 1368430220932662.

Glanville, J. L., \& Paxton, P. (2007). How do we learn to trust? A confirmatory tetrad analysis of the sources of generalized trust. Social Psychology Quarterly, 70(3), 230-242.

Goldschmidt, T., Hällsten, M., Rydgren, J. (2017). Are they hunkering down? Revisiting the relationship between exposure to ethnic diversity, intergroup contact, and group trust. The Department of Sociology Working Paper Series. Preprint. https://doi.org/10.17045/sthlmuni.14039819.v1

Gundelach, B., \& Freitag, M. (2014). Neighbourhood diversity and social trust: An empirical analysis of interethnic contact and group-specific effects. Urban Studies, 51(6), 1236-1256.

Hainmueller, J., \& Hopkins, D. J. (2014). Public attitudes toward immigration. Annual Review of Political Science, 17, 225-249.

Hangartner, D., Dinas, E., Marbach, M., Matakos, K., \& Xefteris, D. (2019). Does exposure to the refugee crisis make natives more hostile? American Political Science Review, 113(2), 442-455.

Hardin, R. (Ed.). (2003). Distrust. Russell Sage Foundation.

Henriksen L.S., Strømsnes K., Svedberg L. (2019). Understanding Civic Engagement in the Scandinavian Context. In Henriksen L., Strømsnes K., Svedberg L. (Eds), Civic engagement in scandinavia. Nonprofit and Civil Society Studies (An International Multidisciplinary Series). Cham: Springer. https:// doi.org/10.1007/978-3-319-98717-0_1

Hopkins, D. J. (2010). Politicized places: Explaining where and when immigrants provoke local opposition. American Political Science Review, 104(1), 40-60. https://doi.org/10.1017/S00030554099903 60

Laurence, J. (2020). Cohesion through participation? Youth engagement, interethnic attitudes, and pathways of positive and negative intergroup contact among adolescents: A quasi-experimental field study. Journal of Ethnic and Migration Studies, 46(13), 2700-2722.

Laurence, J., \& Bentley, L. (2016). Does ethnic diversity have a negative effect on attitudes towards the community? A longitudinal analysis of the causal claims within the ethnic diversity and social cohesion debate. European Sociological Review, 32(1), 54-67.

Laurence, J., Schmid, K., \& Hewstone, M. (2018). Ethnic diversity, inter-group attitudes and countervailing pathways of positive and negative inter-group contact: An analysis across workplaces and neighbourhoods. Social Indicators Research, 136(2), 719-749.

Laurence, J., Schmid, K., \& Hewstone, M. (2019). Ethnic diversity, ethnic threat, and social cohesion: $(\mathrm{Re})$-evaluating the role of perceived out-group threat and prejudice in the relationship between 
community ethnic diversity and intra-community cohesion. Journal of Ethnic and Migration Studies, 45(3), 395-418.

Leszczensky, L., \& Pink, S. (2019). What drives ethnic homophily? A relational approach on how ethnic identification moderates preferences for same-ethnic friends. American Sociological Review, 84(3), 394-419.

Loxbo, K. (2018). Ethnic diversity, out-group contacts and social trust in a high-trust society. Acta Sociologica, 61(2), 182-201.

McPherson, M., Smith-Lovin, L., \& Cook, J. M. (2001). Birds of a feather: Homophily in social networks. Annual Review of Sociology, 27(1), 415-444.

Munobwa, J. S., Ahmadi, F., \& Darvishpour, M. (2021). Diversity barometer 2020: Attitudes towards immigration and ethnic diversity in Sweden. Social Sciences, 10(10), 401.

Pettigrew, T. F., \& Tropp, L. R. (2006). A meta-analytic test of intergroup contact theory. Journal of Personality and Social Psychology, 90(5), 751.

Pettigrew, T. F., Tropp, L. R., Wagner, U., \& Christ, O. (2011). Recent advances in intergroup contact theory. International Journal of Intercultural Relations, 35(3), 271-280.

Putnam, R. D. (2007). E pluribus unum: Diversity and community in the twenty-first century the 2006 Johan Skytte Prize Lecture. Scandinavian Political Studies, 30(2), 137-174.

Schmidt-Catran, A. W., \& Fairbrother, M. (2016). The random effects in multilevel models: Getting them wrong and getting them right. European Sociological Review, 32(1), 23-38.

Statistics Sweden. (2020). Statistikdatabasen, Swedish and foreign-born population by region, age and sex.

Stolle, D., Soroka, S., \& Johnston, R. (2008). When does diversity erode trust? Neighborhood diversity, interpersonal trust and the mediating effect of social interactions. Political Studies, 56(1), 57-75.

Strömblad, P., \& Malmberg, B. (2016). Ethnic segregation and xenophobic party preference: Exploring the influence of the presence of visible minorities on local electoral support for the Sweden Democrats. Journal of Urban Affairs, 38(4), 530-545.

Thomsen, J. P. F., Fenger, J., \& Jepsen, N. R. (2021). The experiential basis of social trust towards ethnic outgroup members. Social Indicators Research, 154(1), 191-209.

Trustbarometer (2017). https://www.esh.se/forskning/forskningsprojekt/2018-11-08-tillitsbarometern. html

Uslaner, E. M. (2002). The moral foundations of trust. Cambridge University Press.

Uslaner, E. M. (2012). Segregation and mistrust: Diversity, isolation, and social cohesion. Cambridge University Press.

Uslaner, E. M. (2015). Diversity, segregation, and trust. In Koopmans, Lancee \& Schaeffer (Eds.) Social cohesion and immigration in Europe and North America, Routledge.

Van der Meer, T., \& Tolsma, J. (2014). Ethnic diversity and its effects on social cohesion. Annual Review of Sociology, 40(1), 459-478.

Wallman Lundåsen, S., \& Wollebæk, D. (2013). Diversity and community trust in Swedish local communities. Journal of Elections, Public Opinion \& Parties, 23(3), 299-321.

Wollebæk, D., Lundåsen, S. W., \& Trägårdh, L. (2012). Three forms of interpersonal trust: Evidence from Swedish municipalities. Scandinavian Political Studies, 35(4), 319-346.

Publisher's Note Springer Nature remains neutral with regard to jurisdictional claims in published maps and institutional affiliations. 